\title{
ВMJ Global Health Are current preventive chemotherapy strategies for controlling and eliminating neglected tropical diseases cost-effective?
}

\author{
Hugo C Turner, ${ }^{1,2,3}$ Wilma A Stolk, ${ }^{4}$ Anthony W Solomon, ${ }^{5}$ Jonathan D King, ${ }^{5}$ \\ Antonio Montresor, ${ }^{5}$ David H Molyneux, ${ }^{6}$ Jaspreet Toor ${ }^{1,7}$
}

To cite: Turner HC, Stolk WA, Solomon AW, et al. Are current preventive chemotherapy strategies for controlling and eliminating neglected tropical diseases costeffective?BMJ Global Health 2021;6:e005456. doi:10.1136/ bmjgh-2021-005456

Handling editor Seye Abimbola

Received 19 February 2021

Revised 23 April 2021

Accepted 26 April 2021
Check for updates

(c) World Health Organization 2023. Licensee BMJ.

For numbered affiliations see end of article.

Correspondence to

Dr Hugo C Turner;

hugo.turner@imperial.ac.uk

\section{ABSTRACT}

Neglected tropical diseases (NTDs) remain a significant cause of morbidity and mortality in many low-income and middle-income countries. Several NTDs, namely lymphatic filariasis, onchocerciasis, schistosomiasis, soil-transmitted helminthiases (STH) and trachoma, are predominantly controlled by preventive chemotherapy (or mass drug administration), following recommendations set by the WHO. Over one billion people are now treated for NTDs with this strategy per year. However, further investment and increased domestic healthcare spending are urgently needed to continue these programmes. Consequently, it is vital that the cost-effectiveness of preventive chemotherapy is understood. We analyse the current estimates on the cost per disability-adjusted life year (DALY) of the preventive chemotherapy strategies predominantly used for these diseases and identify key evidence gaps that require further research. Overall, the reported estimates show that preventive chemotherapy is generally cost-effective, supporting WHO recommendations. More specifically, the cost per DALY averted estimates relating to community-wide preventive chemotherapy for lymphatic filariasis and onchocerciasis were particularly favourable when compared with other public health interventions. Cost per DALY averted estimates of school-based preventive chemotherapy for schistosomiasis and STH were also generally favourable but more variable. Notably, the broader socioeconomic benefits are likely not being fully captured by the DALYS averted metric. No estimates of cost per DALY averted relating to community-wide mass antibiotic treatment for trachoma were found, highlighting the need for further research. These findings are important for informing global health policy and support the need for continuing NTD control and elimination efforts.

\section{INTRODUCTION}

The neglected tropical diseases (NTDs) are a diverse group of conditions that are most prevalent in populations living in poverty. ${ }^{1}$ Several of the most prevalent NTDs, namely lymphatic filariasis, onchocerciasis, schistosomiasis, soil-transmitted helminthiases (STH)

\section{Summary box}

$\Rightarrow$ Several of the most prevalent neglected tropical diseases (NTDs), namely lymphatic filariasis, onchocerciasis, schistosomiasis, soil-transmitted helminthiases and trachoma, are controlled at least in part by preventive chemotherapy (or mass drug administration).

$\Rightarrow$ Many studies have found preventive chemotherapy to be a cost-effective strategy for controlling these NTDs.

$\Rightarrow$ These findings have important implications for advocacy groups and potential funders and will be useful for decision-makers in endemic countries to justify the increased domestic healthcare spending needed for NTD programmes.

$\Rightarrow$ Further work is needed to inform preventive chemotherapy programmes and the economics of elimination programmes, particularly for trachoma where no relevant estimates were found.

and trachoma, are controlled at least in part by preventive chemotherapy (also referred to as mass drug administration $)^{2}$ : the largescale distribution of medicines to eligible populations within an endemic area, without diagnosing or testing individual participants for current infection. ${ }^{3}$ Some treatment programmes specifically target school-aged children (SAC), whereas others target the whole community. ${ }^{3}$ Within WHO guidelines, different preventive chemotherapy strategies may be recommended depending on prevalence of infection for these NTDs. Generally, there is a minimum prevalence below which mass treatment is not recommended. ${ }^{3}$

When first used, preventive chemotherapy was often performed by mobile teams of paid health workers. ${ }^{4}$ However, in the mid-1990s, onchocerciasis programmes shifted to using community-directed distributors. ${ }^{4-6}$ Later other NTD programmes also started using 

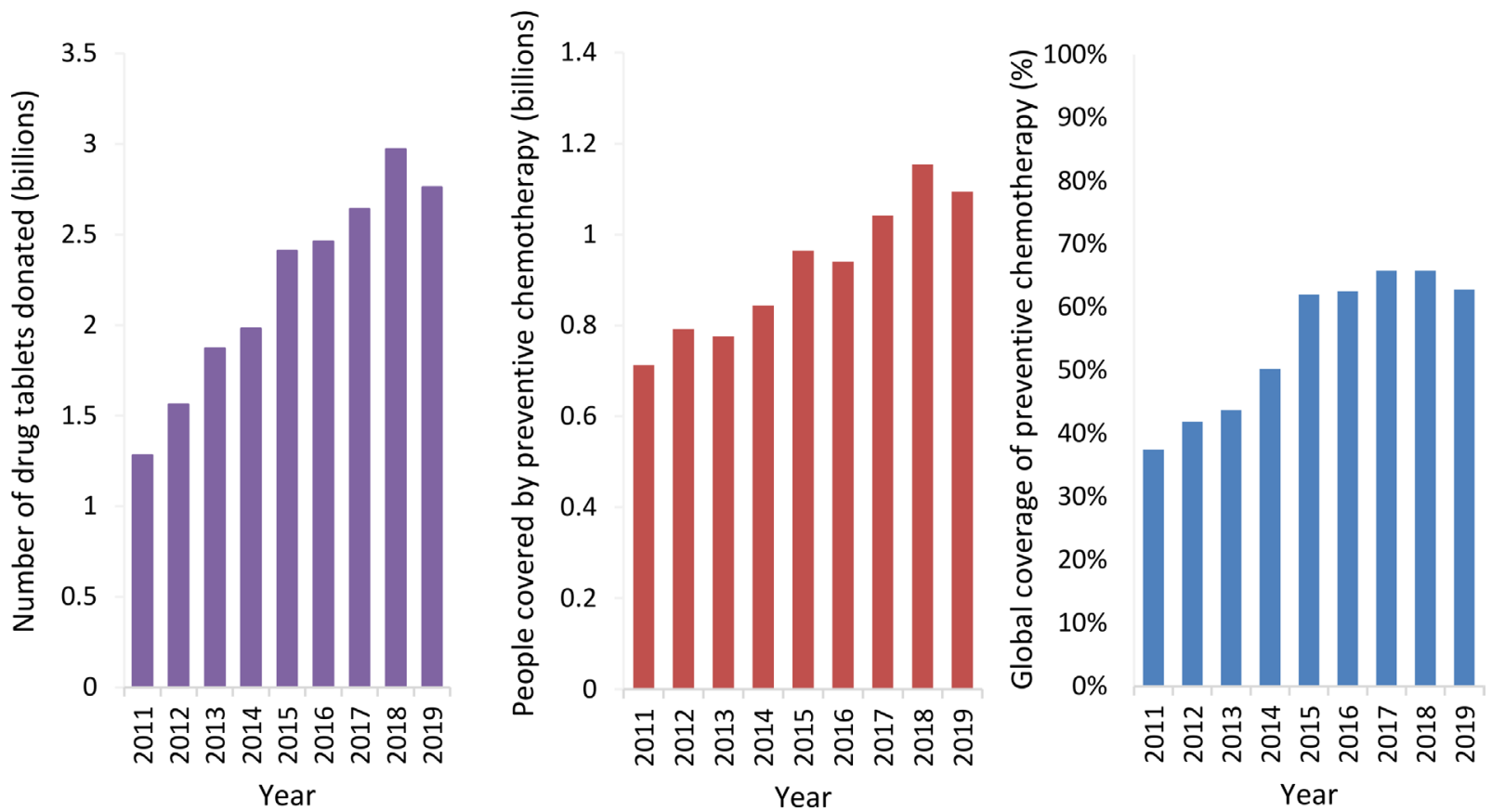

Figure 1 Summary of global preventive chemotherapy for lymphatic filariasis, onchocerciasis, schistosomiasis, soiltransmitted helminthiases and trachoma from 2011 to 2019. Data adapted from the WHO NTD progress dashboard. ${ }^{100}$ Global coverage is based on the proportion of the population requiring treatment that is treated.

community volunteers, and school-based preventive chemotherapy programmes incorporated teachers and other school officials as part of the NTD workforce..$^{3-9}$ This resulted in a notable reduction in delivery costs and an increase in programmatic feasibility, allowing preventive chemotherapy programmes to expand. Over the last 20 years, the coverage of preventive chemotherapy has increased significantly (figure 1), supported by generous drug donations from the pharmaceutical industry (table 1).$^{1011}$ In 2019 alone, 1.63 billion preventive chemotherapy treatments were delivered for NTDs worldwide. ${ }^{12}$

These NTDs cause a significant health burden, particularly among the world's poorest and most marginalised in low-income and middle-income countries. ${ }^{13}$ de Vlas et $a l^{4}$ estimated that if the 2020 goals were achieved for these five NTDs, 328 million disability-adjusted life years (DALYs) would be averted between 2011 and 2030. In addition to their health impact as measured by DALYs, these diseases cause a significant social and economic burden which can exacerbate the cycle of poverty forming an obstacle to sustainable development. ${ }^{1516}$

WHO and its partners have published a 2021-2030 road map for NTDs ${ }^{11}$ (table 1) which lays out a pathway to sustain the gains and accelerate progress towards the control and elimination of these diseases. Further integration of NTD programmes into local health systems and greater country ownership, including a shift towards increased domestic healthcare spending, will likely be required, ${ }^{17-19}$ and has been set out within the road map as one of three strategic shifts for the coming decade. As the road map calls for country-led, evidence-based planning, there is a need for generation and use of relevant cost and cost-effectiveness data. It is therefore vital that there is a wider understanding of the evidence on the cost-effectiveness of preventive chemotherapy. This will inform future policy decisions and facilitate ongoing provision of resources for programmes.

This paper provides an evaluation of the existing evidence on the cost-effectiveness of the predominantly implemented preventive chemotherapy strategies for lymphatic filariasis, onchocerciasis, schistosomiasis, STH and trachoma. In addition, we highlight areas that require further research.

\section{CURRENT COST-EFFECTIVENESS ESTIMATES}

Cost-effectiveness analyses compare the costs and health effects of an intervention. The morbidities related to these NTDs are complex; infection can lead to different sequelae. Consequently, a variety of different effectiveness metrics have been generated by cost-effectiveness analyses of interventions against these NTDs, including infections averted, disease cases or types of morbidity averted, heavy infections averted and DALYs averted..$^{20-23}$

DALYs are a measure of disease burden and are calculated as the sum of the years of life lost due to premature mortality and the years of healthy life lost due to disability. ${ }^{24}$ One DALY can be interpreted as 1 year of 'healthy' life lost.

DALYs averted are a more standardised and comprehensive effectiveness metric than disease cases averted and allow cost-effectiveness estimates to be directly compared between diseases. They are typically the preferred effectiveness metric for interventions in low and lower-middle income countries. Therefore, published 
Table 12030 goals and drug donations for lymphatic filariasis, onchocerciasis, schistosomiasis, soil-transmitted helminthiases and trachoma

\begin{tabular}{|c|c|c|c|}
\hline Disease & WHO 2030 goal $^{11}$ & $\begin{array}{l}\text { Coverage } \\
\text { achieved in } \\
2019^{12}\end{array}$ & Drug donor and donation ${ }^{11}$ \\
\hline $\begin{array}{l}\text { Lymphatic filariasis } \\
\text { (elephantiasis) }\end{array}$ & $\begin{array}{l}\text { Elimination as a public health problem } \\
\text { (infection sustained below transmission } \\
\text { assessment survey thresholds for at } \\
\text { least } 4 \text { years after stopping mass drug } \\
\text { administration; availability of essential } \\
\text { package of care in all areas of known } \\
\text { patients) validated in } 58(81 \%) \text { countries }\end{array}$ & $62.7 \%$ & $\begin{array}{l}\text { Eisai: up to } 400 \text { million diethylcarbamazine } \\
\text { (DEC) tablets per year until elimination } \\
\text { Merck Sharp \& Dohme: unlimited ivermectin } \\
\text { in settings co-endemic with onchocerciasis } \\
\text { (recently expanded to include up to } \\
250 \text { million tablets per year through } 2025 \text { for } \\
\text { communities eligible for the triple-therapy } \\
\text { mass drug administration regimen of } \\
\text { ivermectin, DEC and albendazole) } \\
\text { GlaxoSmithKline: up to } 600 \text { million } \\
\text { albendazole tablets annually until elimination }\end{array}$ \\
\hline $\begin{array}{l}\text { Onchocerciasis (river } \\
\text { blindness) }\end{array}$ & $\begin{array}{l}\text { Elimination of transmission verified in } 12 \\
(31 \%) \text { countries }\end{array}$ & $62.8 \%$ & $\begin{array}{l}\text { Merck Sharp \& Dohme: ivermectin for as long } \\
\text { as needed }\end{array}$ \\
\hline $\begin{array}{l}\text { Schistosomiasis } \\
\text { (bilharzia) }\end{array}$ & $\begin{array}{l}\text { Elimination as a public health problem } \\
\text { (currently defined as }<1 \% \text { proportion of heavy } \\
\text { intensity Schistosoma infections) validated in } \\
78(100 \%) \text { countries }\end{array}$ & $\begin{array}{l}\text { SAC: } 59.3 \% \\
\text { Adults: } 14.3 \%\end{array}$ & $\begin{array}{l}\text { Merck KGaA: up to } 250 \text { million praziquantel } \\
\text { tablets annually for an unlimited period }\end{array}$ \\
\hline $\begin{array}{l}\text { Soil-transmitted } \\
\text { helminthiases } \\
\text { (intestinal helminths) }\end{array}$ & $\begin{array}{l}\text { Elimination as a public health problem } \\
(<2 \% \text { proportion of soil-transmitted } \\
\text { helminth infections of moderate and heavy } \\
\text { intensity due to Ascaris lumbricoides, } \\
\text { Trichuris trichiura, Necator americanus and } \\
\text { Ancylostoma duodenale) validated in } 96 \\
(96 \%) \text { countries }\end{array}$ & $\begin{array}{l}\text { Pre-SAC: } 36.8 \% \\
\text { SAC: } 57.8 \%\end{array}$ & $\begin{array}{l}\text { Johnson \& Johnson: } 200 \text { million mebendazole } \\
\text { tablets annually for SAC until } 2025 \\
\text { GlaxoSmithKline: } 200 \text { million albendazole } \\
\text { tablets annually for SAC }\end{array}$ \\
\hline Trachoma & $\begin{array}{l}\text { Elimination as a public health problem ((i) } \\
\text { a prevalence of trachomatous trichiasis } \\
\text { 'unknown to the health system' of }<0.2 \% \\
\text { in } \geq 15 \text {-year-olds in each formerly endemic } \\
\text { district; (ii) a prevalence of trachomatous } \\
\text { inflammation - follicular in children aged } \\
1-9 \text { years of }<5 \% \text { in each formerly endemic } \\
\text { district; and (iii) written evidence that the } \\
\text { health system is able to identify and manage } \\
\text { incident cases of trachomatous trichiasis, } \\
\text { using defined strategies, with evidence of } \\
\text { appropriate financial resources to implement } \\
\text { those strategies) validated in } 64 \text { ( } 100 \%) \\
\text { countries }\end{array}$ & $57.2 \%$ & $\begin{array}{l}\text { Pfizer: unlimited quantity of azithromycin until } \\
2025\end{array}$ \\
\hline
\end{tabular}

Pre-SAC, Pre-school-age children; SAC, School-age children.

literature reporting a cost per DALY averted are the focus of our analysis and we report the estimates related to the preventive chemotherapy strategies predominantly used for these diseases (see box 1). These were assumed to be annual community-wide treatment for lymphatic filariasis, onchocerciasis and trachoma, annual school-based treatment for schistosomiasis and annual or biannual school-based treatment for STH (box 1). Further information regarding cost-effectiveness studies and other economic evaluations relating to these NTDs can be found in previously published reviews. ${ }^{20-23}$ Information on how the literature was identified is provided in box 1 .

It is important to note that we have focused on cost-effectiveness estimates reporting cost per DALY averted relating to the predominantly used preventive chemotherapy strategies for each disease (box 1). However, for some diseases other strategies are also performed (such as treatment of adults for schistosomiasis and treatment of pre-SAC for STH). Estimates also exist relating to alternative strategies, as well as other types of health economic assessments, ${ }^{20-23} 25$ including studies estimating economic and educational benefits. ${ }^{26}$

\section{How the effectiveness of preventive chemotherapy was quantified}

Several methodological factors can influence the effectiveness estimates of preventive chemotherapy, such as the time horizon, the setting under investigation, the modelling approach and the DALY calculation. These 


\section{Box 1 Selection criteria}

The focus of this analysis was on published estimates reporting a cost per disability-adjusted life year (DALY) averted. We summarised the estimates from published literature reporting average costeffectiveness ratios related to cost per DALY averted for the predominantly used preventive chemotherapy strategies relative to a do-nothing comparator. The predominantly used strategies were assumed to be annual community-wide treatment for lymphatic filariasis, onchocerciasis and trachoma, annual school-based treatment for schistosomiasis and annual or biannual schoolbased treatment for soil-transmitted helminthiases (STH). This was informed by the WHO Preventive Chemotherapy and Transmission Control databank (note that for some diseases these are not the only strategies used). ${ }^{101}$ We included estimates related to stand-alone preventive chemotherapy and excluded those in which preventive chemotherapy was combined with additional interventions, such as antibiotic mass drug administration and surgery for trachoma. No time restrictions were made regarding which estimates were included. Cost-effectiveness estimates relating to alternative strategies (as well as incremental cost-effectiveness ratios of scaling up preventive chemotherapy programmes) and estimates relating to treatment in areas below the currently recommended prevalence cut-offs for mass treatment were excluded. ${ }^{3}$ Studies reporting metrics other than a cost per DALY averted were excluded.

We identified the relevant studies from previously published disease-specific systematic reviews ${ }^{20-23}$ and also carried out an updated search for more recent data published in the peer-reviewed press. For trachoma, no previously published systematic review was available and therefore the studies were only identified via the search. Updated searches were of MEDLINE, PubMed and in the reference lists from relevant published articles found within those searches. We used combinations of the search terms 'lymphatic filariasis', 'onchocerciasis', 'schistosomiasis', 'soil-transmitted helminthiases (STH)', 'ascaris', 'trichuris', 'hookworm', 'trachoma', 'costeffectiveness', 'cost-utility', 'cost per DALY averted'. No language or date restrictions were used. Note: although searches were conducted, this is not a formal systematic review.

need to be considered when comparing different studies (table 2).

A key consideration is the time horizon of the analyses which determines the duration over which outcomes and costs are calculated (table 2). If the time horizon is too short, the long-term benefits of preventive chemotherapy may not be accounted for, underestimating its costeffectiveness. As time horizons vary between studies, this parameter is likely a key driver of variability among the estimates. Importantly, many of the studies had time horizons under 10 years and therefore did not fully capture longer-term costs and benefits associated with achieving NTD control or elimination (table 2).

A further important consideration when comparing different studies is the geographical and epidemiological setting being investigated. Some studies focused on a specific area whereas others focused on a whole regional or global programme. The baseline prevalence of infection varied across studies. This impacted effectiveness estimates, because in general, the higher the baseline prevalence, the greater the health impact of preventive chemotherapy and therefore the greater the cost-effectiveness (table 2). Most studies investigated the effect of preventive chemotherapy on one NTD, though a few studies considered the effect on two NTDs and one study considered the simultaneous effect on three NTDs (table 2).

Various approaches have been used in costeffectiveness studies to quantify the impact of preventive chemotherapy, ranging from back-of-the-envelope calculations to dynamic transmission models (table 2). Dynamic transmission models are often used to estimate the population-level effectiveness of preventive chemotherapy as such models can account for the intervention's indirect benefits on those not treated and the densitydependent processes which govern infection transmission. ${ }^{25}$ Static models do not account for these processes and therefore may not capture the full benefits of preventive chemotherapy.

DALY calculations are highly sensitive to changes in assigned disability weights and which sequelae of infection are included. Notably, the disability weights used for NTDs have changed significantly since Global Burden of Disease Study (GBD) $2010^{27} 28$ (see online supplemental Table S1) for the disability weights used by the GBD 2019 for these NTDs). For example, the disability weight for blindness decreased (somewhat controversially) from 0.60 to $0.19{ }^{29}{ }^{30}$ This is an important source of variation in costeffectiveness estimates and needs to be considered when interpreting available data. DALY calculations for schistosomiasis and STH have been a source of debate and various approaches have been taken in different studies. ${ }^{231-36}$ For example, cognitive impairment was removed as a quantifiable sequela of STH infection for GBD 2010. Although this was justified by a perceived lack of evidence of causation, ${ }^{37}$ it is an area of debate within the field ${ }^{38}{ }^{39}$ It may be difficult to reach a definitive conclusion regarding the impact of STH on cognition and this should be acknowledged when interpreting cost-effectiveness analyses. Due to the uncertainties associated with the DALY calculations for NTDs, a degree of caution should be employed when interpreting cost-effectiveness estimates, particularly for targeting schistosomiasis and STH in different age groups or in areas of low prevalence and intensity of infection. ${ }^{40}$

It is important to consider that the framework for estimating DALYs does not necessarily fully summarise the disease burden of these NTDs. As examples, onchocerciasis-associated epilepsy ${ }^{41}{ }^{42}$ is not fully accounted for, the potential mental health burden for some of the sequelae is not always considered ${ }^{434}$ and (due in part to lack of data) potential excess mortality conferred by these diseases is not always included. This could lead to the health impacts being underestimated. Additionally, we recognise that the DALY framework fails to acknowledge the implications of context on the burden of disease, with those living in poverty or with poor access to healthcare typically affected far more than people in higher socioeconomic strata or than those with access to affordable healthcare. ${ }^{45}$ 


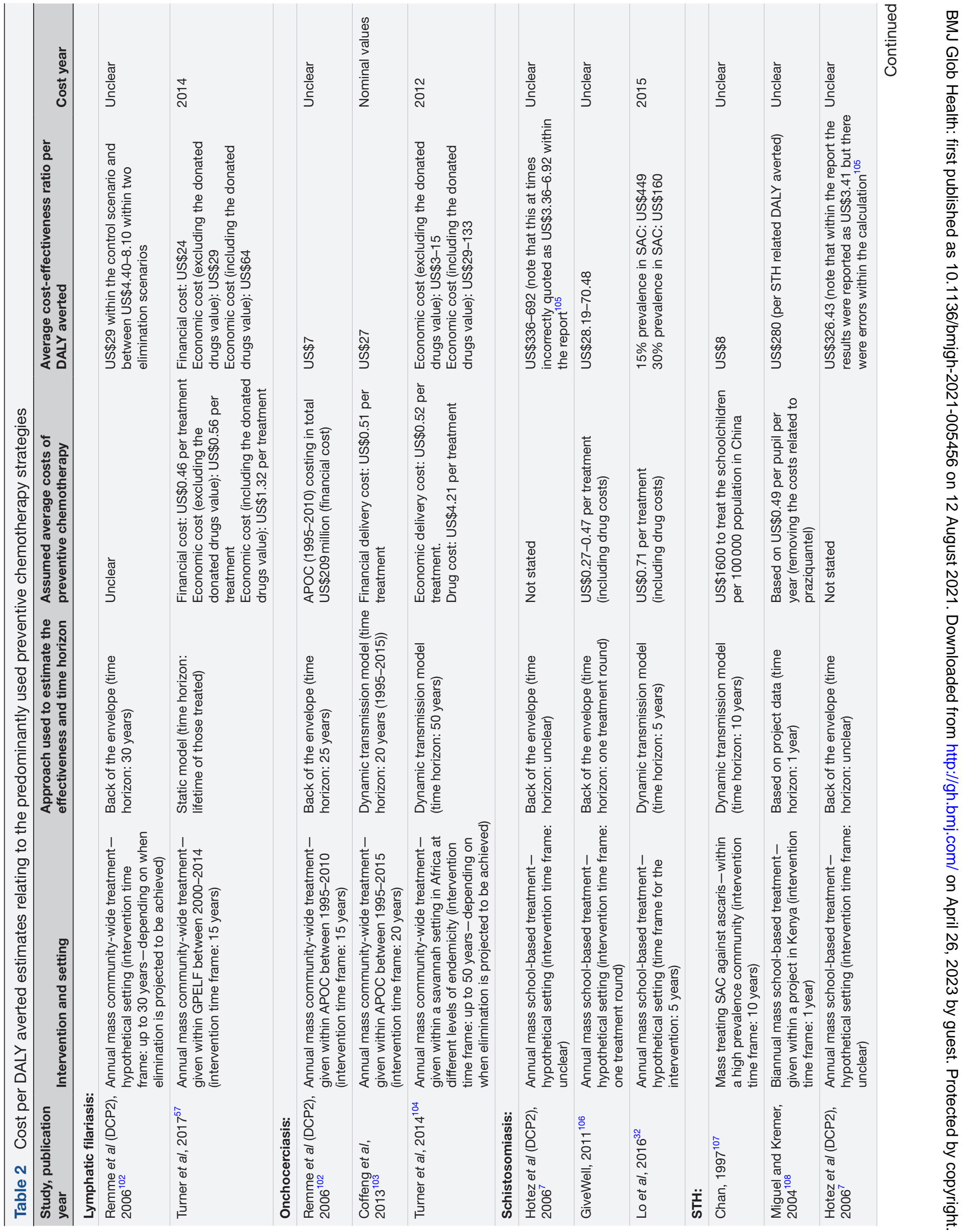




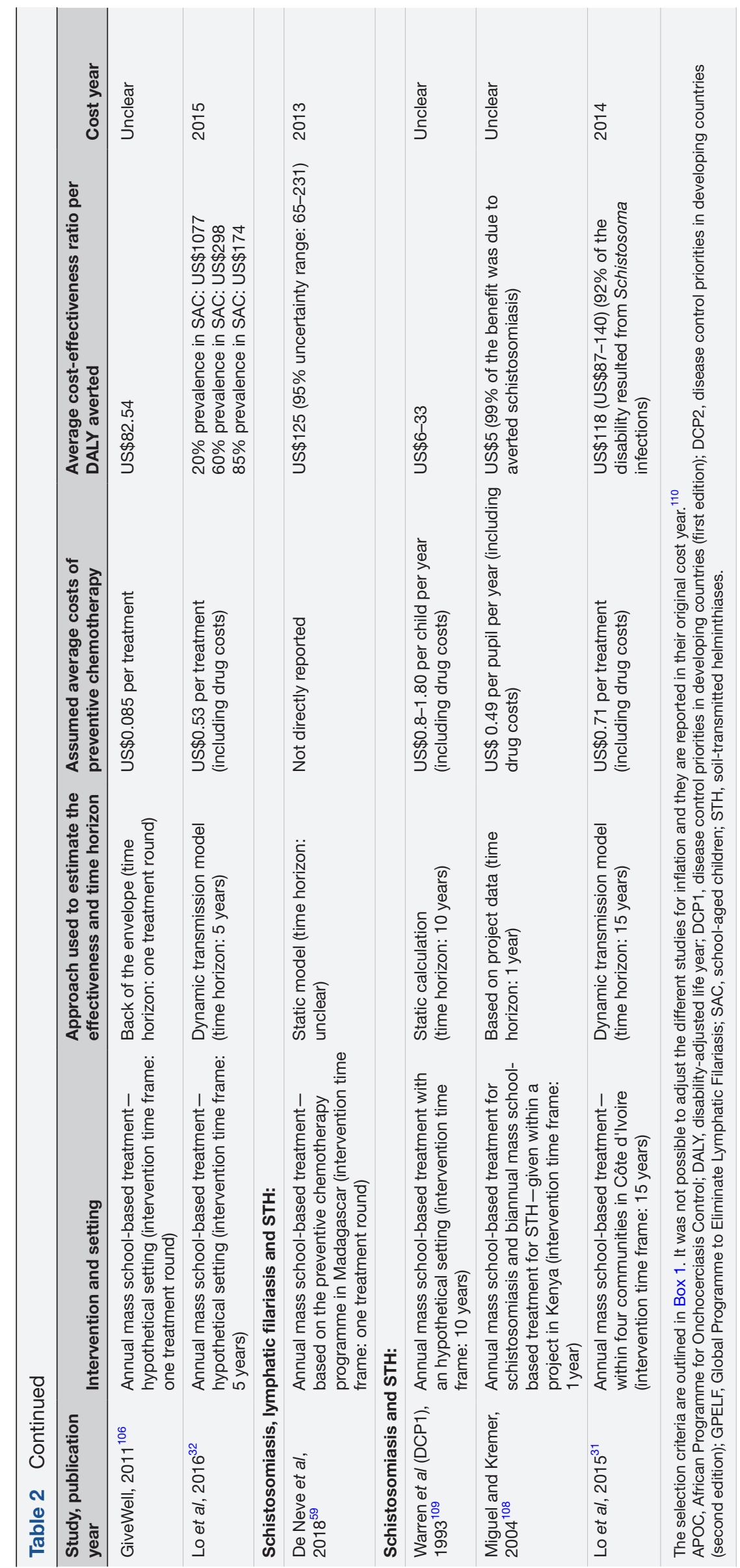




\section{How costs of preventive chemotherapy were quantified}

The way in which costs are quantified will impact the estimates of the cost-effectiveness of preventive chemotherapy. The methods used to parameterise the costs differed widely across studies: some were based on primary data whereas others used assumed crude benchmarks. The delivery costs were generally assumed to be around US $\$ 0.50$ per treatment (table 2), consistent with current benchmarks. ${ }^{46}$ However, delivery costs vary across different settings with the size of the target population being a key driver in this variation. ${ }^{20-2346-50}$ This is because delivery costs for preventive chemotherapy tend to show economies of scale that is, as the number of people treated increases, the cost per treatment decreases. ${ }^{471}$

It should be noted when looking at the assumed costs that the annual costs of preventive chemotherapy also change depending on the distribution method. The least costly and resource intensive strategy is likely to be incorporating the distribution into an established health system platform/existing programme (such as a Child Health Day), followed by school-based treatment and then community-wide treatment. ${ }^{2152}$ In addition, the costs are influenced by how the strategy is implemented. For example, the use of volunteer community distributors or teachers would be cheaper than paid health workers. ${ }^{21} 53$

When looking at these studies, it is important to consider whether they are using financial or economic costs (table 2). Financial costs represent the amount paid for the goods, resources and services that are purchased. Economic costs conceptualise costs more broadly and represent the full value of the resources used for an intervention, including the value of donated resources, such as the unpaid time of community health volunteers. ${ }^{53}$ It is typically recommended to use economic costs within economic evaluations. ${ }^{5455}$ Not all studies clearly reported the type of cost data used or their source (table 2).

As drugs used for these NTDs are typically donated (table 1), they are often not counted as a financial cost for the health ministry within preventive chemotherapy programmes. Their value can, however, be included as an economic cost, depending on the viewpoint from which the intervention's costs and consequences are evaluated (ie, the study's perspective). The value of donated medicines can be a significant cost. For example, it has been estimated that the value of pharmaceutical partners' donated products for the 10 NTDs included in the London Declaration was US\$2-3 billion annually. ${ }^{56} \mathrm{In}$ practice, it is difficult to estimate the true economic cost of drugs that are donated for preventive chemotherapy programmes, as the assumed costs/value of these drugs varies and the correct value to use is debatable..$^{20-235758}$ If and how the donated drugs are valued are sources of variation in cost-effectiveness estimates of preventive chemotherapy, particularly for ivermectin and azithromycin as the economic values reported by the companies donating them are higher than those for other donated drugs. Such variation needs to be considered when interpreting the results from older costing and cost-effectiveness studies. Furthermore, when a commitment has been made to donate a drug for as long as needed (table 1), it is debatable whether its economic value should be included within economic evaluations.

\section{Estimates of the cost per DALY averted}

Table 2 and box 2 summarise the key cost-effectiveness estimates in terms of DALYs averted relating to the predominantly used preventive chemotherapy strategies. These estimates generally represent the overall mean cost-effectiveness of a NTD preventive chemotherapy programme, or its cost-effectiveness in one specific setting. Importantly, most of the estimates relate to one disease. However, a study by De Neve et a $a \tilde{l}^{9}$ investigated the cost-effectiveness of school-based preventive chemotherapy for multiple diseases (lymphatic filariasis, schistosomiasis and STH), highlighting that the overall costeffectiveness of preventive chemotherapy depends on how many NTDs treated by the distributed medicines are co-endemic in the location under consideration. Notably, none of the estimates considered the impact of the preventive chemotherapy on non-targeted diseases.

Overall, the cost-effectiveness estimates of preventive chemotherapy against lymphatic filariasis and onchocerciasis that we identified (US\$3-133 per DALY averted; table 2) were favourable compared with the main costeffectiveness thresholds used for low-income countries (outlined in box 3) and compared with other interventions conducted in low-income and middle-income countries, with estimates on par with those associated with interventions for other major global health problems. For example, supplying insecticide-treated nets for malaria has been estimated to cost US\$61-94 per DALY averted in three African settings (2012 prices). ${ }^{60-62}$ A comprehensive list of cost-effectiveness estimates for a range of public health interventions is provided by Horton et al. ${ }^{63}$

The estimated cost-effectiveness of preventive chemotherapy for schistosomiasis and STH was also generally favourable (US\$8-1077 per DALY averted; table 2) but more variable than estimates for lymphatic filariasis and onchocerciasis. For schistosomiasis and STH, the estimated cost per DALY averted was generally found to be below a cost-effectiveness threshold less than half the country's per capita GDP, ${ }^{64} 65$ with some more promising estimates below the disease control priorities (third edition) US $\$ 200$ per DALY averted threshold. ${ }^{66}$ Here, the highest estimate of US $\$ 1077$ falls above these conservative thresholds (Box 3 ) but this is related to a $20 \% \mathrm{STH}$ prevalence setting below which preventive chemotherapy is not recommended. In addition to the prevalence setting, variation in these estimates is likely to be partly driven by the methods used to calculate corresponding DALY burdens and how they are changing over time. It is debatable whether the number of DALYs averted (which focus on health) are truly capturing all long-term benefits of treating schistosomiasis and STH. Hicks $e t a l^{67}$ recently demonstrated significant long-term economic 
Box 2 Summary of the cost per disability-adjusted life year (DALY) averted estimates

Lymphatic filariasis: Turner et $a^{57}$ estimated that the cost per DALY averted for preventive chemotherapy delivered within the Global Programme to Eliminate Lymphatic Filariasis was US\$24 when using financial costs, US\$29 when using economic costs excluding the value of the donated drugs and US\$64 when using economic costs including the value of the donated drugs (2014 prices). Analysis within the second edition of the disease control priorities in developing countries (DCP2) ${ }^{102}$ estimated that lymphatic filariasis related preventive chemotherapy costs approximately US\$29 per DALY averted within a control scenario and between US\$4.40-8.10 per DALY averted (*) within two elimination scenarios.

Onchocerciasis: Based on dynamic transmission modelling and assuming and economic delivery cost of US\$0.52 per treatment, Turner et al ${ }^{104}$ estimated that long-term preventive chemotherapy in an African savannah setting cost between US\$3-15 per DALY averted (2012 prices) depending on the assumed endemicity level and excluding the value of the donated drugs. The results changed to US\$29-133 per DALY averted (2012 prices) when including the additional economic value of the donated ivermectin. ${ }^{104}$ Coffeng et $a^{103}$ estimated based on the simulated benefits and reported financia costs of the African Programme for Onchocerciasis Control occurring between 1995-2015, a cost of US\$27 per DALY averted (nominal values). Analysis within the DCP2 ${ }^{102}$ estimated that onchocerciasis related preventive chemotherapy costs approximately US\$7 per DALY averted $\left({ }^{*}\right)$.

Schistosomiasis: Lo et $a \beta^{31}$ estimated the cost-effectiveness of school-based preventive chemotherapy in four communities in Côte d'Ivoire, resulting in an average cost per DALY averted of US\$118 (2014 prices). Most (92\%) of the disability resulted from Schistosoma infections. Miguel and Kremer ${ }^{108}$ estimated that within their study of school-based preventive chemotherapy in Kenya, it cost US\$5 per DALY averted (*) with $99 \%$ of the benefit due to averted schistosomiasis. Analysis within the DCP2 ${ }^{7}$ estimated that treating school-aged children (SAC) for schistosomiasis costs US\$336-692 per DALY averted $\left(^{*}\right)$ (note that this is incorrectly quoted as US\$3.36-6.92 within the published report). ${ }^{105}$ GiveWell estimated that school-based preventive chemotherapy for schistosomiasis cost US\$28.19-70.48 per DALY averted (*). ${ }^{106}$ Lo et a ${ }^{32}$ also showed that the cost-effectiveness of school-based preventive chemotherapy against schistosomiasis was highly influenced by the local prevalence of infection-15\% prevalence: US\$449 per DALY averted, and 30\% prevalence: US $\$ 160$ per DALY averted (2015 prices). Community-wide preventive chemotherapy tended not to be more cost-effective, ${ }^{23} 3132$ that is, it did not have a lower cost per DALY averted. However, it could be classed as cost-effective depending on the chosen costeffectiveness threshold.

Soil-transmitted helminthiases (STH): Chan ${ }^{107}$ estimated that treating SAC for Ascaris lumbricoides is highly cost-effective in a high prevalence community; US\$8 per DALY averted (cost year not stated). Analysis within the DCP2 ${ }^{7}$ estimated that treating SAC for STH costs US\$326 per DALY averted (note that within the report the results were reported as US\$3.41 per DALY averted $\left({ }^{\star}\right)$, but there were errors within the calculation). ${ }^{105}$ GiveWell re-estimated the cost-effectiveness (using a different methodology) and obtained an estimate of US\$83 per DALY averted $\left({ }^{*}\right) .{ }^{105106}$ Miguel and Kremer ${ }^{108}$ estimated that within their study the cost per STH-related DALY averted would be US $\$ 280$ $\left.{ }^{(*}\right)$. Lo et $a^{32}$ also showed that the cost-effectiveness of school-based preventive chemotherapy against STH was highly influenced by the

Continued
Box 2 Continued

prevalence of infection-20\% prevalence: US\$1077 per DALY averted $60 \%$ prevalence: US\$298 per DALY averted, 85\% prevalence: US\$174 per DALY averted (2015 prices).

Trachoma: We identified no published cost per DALY averted estimates relating to the currently used strategy of community-wide mass treatment for trachoma using single-dose oral azithromycin. This is now the antibiotic of choice. ${ }^{111}$ In terms of other studies, the Myanmar trachoma control programme was estimated in 1996 by Evans et $\mathrm{al}^{112}$ to have required, over the course of 30 years implementation, only US\$11 for non-surgical interventions (mass treatment with topical antibiotics and community education) for each handicap-adjusted life-year saved. In 2005, Baltussen et al ${ }^{13}$ estimated that targeted mass antibiotic treatment of children for trachoma control purposes cost between I\$9012-65 022 per DALY averted. (International dollars (I\$) are a hypothetical currency unit designed to capture the differences in relative prices across different settings). These estimates included the contemporary market price of azithromycin and its assumed price had a large impact on the results. In practice, virtually all azithromycin used by trachoma programmes is now donated by the manufacturer. When antibiotics are assumed to have no cost to the healthcare system (reflecting donated drugs) or to have been purchased at using generic prices obtainable in India (which are 16 times cheaper), the cost-effectiveness improved, but cost per DALY averted remained relatively high compared with that for other neglected tropical diseases (online supplemental Table S2). In a two-world-region update of the 2005 paper $^{113}$ (again including the cost of azithromycin), Baltussen et $a l,{ }^{114}$ concluded that targeted mass antibiotic treatment of children with azithromycin to control trachoma could be considered cost-effective in the African Region (I\$2101 per DALY averted) but not the South East Asia Region (I\$8051 per DALY averted). ${ }^{114}$ Critiques of these analyses have been published. ${ }^{115116}$ Further analyses are needed before definitive conclusions can be drawn.

Note that it was not possible to adjust the different studies for inflation. *; cost year not clearly stated.

benefits of deworming children, for example, on household income, and its potential social rate of return.

We identified no published estimates of cost per DALY averted relating to community-wide mass treatment for trachoma. Available cost-effectiveness estimates examined the cost of targeting children only (online supplemental Table S2 and box 1); the currently used strategy is community-wide mass treatment. ${ }^{68}$ Effectiveness trials comparing community-wide treatment to treatment of children only have been conducted ${ }^{69}$ but have not changed global policy. Further health economics analyses are needed before more definitive conclusions can be drawn.

\section{Implications of these cost-effectiveness estimates}

Overall, the reported estimates show that the predominantly used preventive chemotherapy strategies are generally cost-effective, thereby supporting WHO recommendations. The generalisability of these estimates depends on multiple factors, including the epidemiological setting and drivers that influence the delivery costs, 


\section{Box 3 Cost-effectiveness thresholds}

To determine whether an intervention is cost-effective, the cost per disability-adjusted life year (DALY) averted is often compared with a cost-effectiveness (willingness to pay) threshold. The most appropriate cost-effectiveness thresholds to use within global health are under debate. ${ }^{117-119}$ When no country-specific threshold has been set, some studies used the cost-effectiveness thresholds set by the Commission on Macroeconomics and Health ${ }^{120}$; namely a cost per DALY averted $<3$ or $<1$ times the country's gross domestic product (GDP) per capita for an intervention to be considered cost-effective or highly cost-effective, respectively. As a benchmark, using the mean GDP for low-income countries in 2019, these thresholds would be US $\$ 2430$ and US\$810, respectively. ${ }^{121}$ However, these thresholds are now considered too high and have been widely criticised. ${ }^{65}$ 117-119 122 The WHO has emphasised that these thresholds were not intended for individual country level-investment decisions but as a broad principle for global or regional consideration. Recent analyses have indicated that a cost-effectiveness threshold of $<0.5$ times the country's GDP per capita would be more appropriate for low-income countries ${ }^{64} 65$; corresponding to US $\$ 405$ based on the average GDP for low-income countries in 2019. ${ }^{121}$ For comparison, the third edition of the Disease Control Priorities project used a threshold of US\$200 per DALY averted to identify priority interventions for consideration in low-income countries. ${ }^{66}$ It is vital that conclusions of economic evaluations are re-interpreted in light of such changes: it is likely that some previous conclusions regarding the interventions or strategies that should be rated cost-effective will no longer hold.

such as remoteness and implementation methods. In terms of epidemiological settings, the estimated health benefits and cost-effectiveness of preventive chemotherapy are generally greater for higher transmission settings. Furthermore, the use of volunteer community distributors could have either positive or negative influences on programmatic outcomes depending on the setting. ${ }^{70}$ Hence, it is important to consider these factors when comparing and interpreting different studies for informing policy decisions.

Although the estimates are encouraging, as the financing of NTD programmes shifts towards a greater contribution from endemic countries, it is important that policymakers consider the cost-effectiveness of these interventions relative to other diseases/priorities in their setting. Budget impact analyses may also be required to identify packages that are too expensive.

In terms of priority setting and policy decisions beyond the cost per DALY averted, it is also important to consider the broader socioeconomic benefits of these NTD programmes. ${ }^{15}$ For example, Redekop et $a l^{16}$ estimated notable social economic benefits would occur from achieving the 2020 targets for these five diseases, both in terms of averted out-of-pocket health expenditure and averted productivity losses (totalling US\$229.5 (162.3344.8) billion in the period 2011-2030 (2015 prices)). Ahuja $e t a l^{26}$ provide a comprehensive summary of the social-economic benefits of deworming. This highlights the broader value of investment in these programmes, particularly in the context of universal health coverage, social protection and reducing inequalities, which are not captured fully by the DALYs averted metric. ${ }^{15}$

\section{FUTURE RESEARCH NEEDS}

Over the last decade, there has been a notable increase in the number of thorough economic evaluations of preventive chemotherapy, increasing the evidence base for this intervention. However, there are many areas in which further research would help to inform policy.

\section{Estimating the health benefits of preventive chemotherapy}

The current framework for estimating DALYs does not necessarily fully summarise the disease burden of these NTDs, potentially underestimating the cost-effectiveness of interventions against them. Further research is needed to comprehensively capture the health benefits of preventive chemotherapy. For example, how to better estimate the health impacts of preventive chemotherapy (particularly when targeting different age groups) is especially important for schistosomiasis and STH, as well as how to quantify the excess mortality associated with these NTDs. In addition, the potential disease burden associated with mental health issues (such as depression) related to these NTDs is not always currently quantified in the standard DALY calculations for some NTD sequelae. Further investigation is needed of the causal relationship between infection and mental health outcomes and their prevalence-not only for the patients but also their caregivers. ${ }^{43} 71$

In future studies, there is a vital need for greater transparency on how numbers of DALYs averted are estimated, particularly with respect to disability weights and their source. Any changes from the approach used within the most recent GBD study needs to be clearly stated and justified.

Cost-effectiveness analyses published to date have typically investigated the impact of preventive chemotherapy on one NTD (table 2). However, preventive chemotherapy for NTDs uses relatively broad-spectrum drugs that can also have an impact on other co-endemic infections, ${ }^{72-77}$ or even on all-cause morbidity and mortality ${ }^{78-80}$ For example, mass ivermectin distribution will also have an impact on strongyloidiasis, scabies, ectoparasites and mosquito mortality. ${ }^{73}{ }^{75} 81$ Consequently, the overall cost-effectiveness of preventive chemotherapy is likely to be underestimated. Further quantification of these auxiliary benefits is needed.

Beyond this, it is important that further research is conducted on the broader non-health-related benefits of preventive chemotherapy, including socioeconomic benefits such as educational and occupational outcomes, productivity gains, and financial protection.

\section{Integrated NTD control}

As NTD programmes push towards greater integration (whereby multiple disease-specific programmes are delivered within a single programme or local health system) and expand their footprint towards the provision 
of universal health coverage, it would be useful for decision-makers to be able to consider cost-effectiveness of integrated NTD control programme packages, rather than stand-alone disease-specific interventions. ${ }^{17-19} \mathrm{~A}$ better understanding of the costs of integrated control programmes ${ }^{85} 86$ and how integration may influence the costs and cost-effectiveness of implementing different control strategies will be required for this.

Further economic evaluations on areas where NTDs are co-endemic are important as a study by Lo $e t a l^{32}$ highlighted that the optimal strategy for schistosomiasis and STH can depend on whether they are co-endemic.

\section{Economic evaluations of alternative preventative chemotherapy strategies and complementary interventions}

A key research area for these NTDs is where and when alternative preventive chemotherapy strategies should be used, such as increasing treatment frequency, targeting different age groups or using a different drug or drug combination. There is a need for more data on the relative costs of different preventive chemotherapy strategies in different settings. For example, there are few primary data on the relative cost of school-based versus community-wide preventive chemotherapy. ${ }^{21}$ Concerningly, many economic evaluations on this topic make assumptions regarding the relative cost of these strategies based on limited data. This is a research gap that needs to be addressed to inform policy. Due to economies of scale and variation in delivery costs between areas, it is usually not possible to generalise cost data from different studies for this purpose. ${ }^{47}$

The potential for leveraging existing delivery platforms, such as child health days or antenatal clinics, could be considered more often when evaluating possible preventive chemotherapy strategies. It is likely that building on established health system platforms to deliver treatment could be cheaper than undertaking dedicated preventive chemotherapy. ${ }^{17}{ }^{87}$ For example, Boselli et $a l^{88}$ estimated that adding deworming into an existing immunisation and vitamin A supplementation campaign would cost less than US\$0.01 per deworming treatment. Further implementation research is needed to assess the possible use of such platforms, ${ }^{89}$ with potential benefits and risks evaluated. This may be particularly important when considering a shift from school-based to communitywide treatment for schistosomiasis and STH. If sufficient coverage of high-risk adults for schistosomiasis and STH could be achieved with established platforms, using them could be more cost-effective than community-wide mass treatment.

More economic evaluations on complementary interventions for these NTDs, such as water, sanitation and hygiene measures, behaviour change interventions and vector control are required. In addition to preventive strategies, it is also important to further evaluate the costeffectiveness of morbidity management strategies.

Further research is required for settings where onchocerciasis is co-endemic with loiasis. Individuals heavily infected with loiasis can experience severe and sometimes fatal neurological sequelae after ivermectin treatment. ${ }^{90}{ }^{91}$ Ivermectin-based mass drug administration is not recommended in hypo-endemic areas for onchocerciasis $(<40 \%$ microfilariae or $<20 \%$ nodules prevalence) that are co-endemic for loiasis. ${ }^{92}$ Consequently, alternative preventive chemotherapy strategies are needed in these settings. One solution is screening every member of the population for loiasis before treatment, treating all those with no or low-intensity Loa loa infection and excluding those with a high-intensity infection. However, such a test-and-(not)-treat approach is more costly than standard preventive chemotherapy. ${ }^{93}$ Lymphatic filariasis control strategies using ivermectin are also impeded in settings co-endemic with loiasis and need to be adapted. In these areas, twice-yearly albendazole monotherapy in combination with coordinated vector control is the recommended strategy. ${ }^{94}$ This strategy will require additional cost due to additional rounds of treatment compared with multi-drug combinations. There is a need for further economic evaluations of the optimal alternative strategies for these settings. Importantly, these will need to consider not only the costs and benefits but also consider the programme goals as a whole and the risk of such settings acting as sources of re-infection to neighbouring populations.

When considering the cost-effectiveness of new strategies or interventions, an important consideration is whether the goal is disease/morbidity control or interruption of transmission. ${ }^{20} 22$ Which strategies are costeffective can be influenced by the goal of the programme. More intensive strategies may not be cost-effective when the goal is controlling morbidity but could be when aiming for interruption of transmission. ${ }^{2022}$ For example, though complementary vector control for lymphatic filariasis has a notable effect on transmission, ${ }^{95} 96$ it may not necessarily be cost-effective for controlling morbidity (ie, in terms of the additional health benefits gained from that setting compared with preventive chemotherapy only) but could be cost-effective in terms of its longterm impact on transmission in the context of achieving elimination goals (such as reducing the risk of resurgence).$^{20}$ The framework for the economic evaluation of elimination strategies needs further investigation and development. In particular, a pressing need is how we evaluate the cost-effectiveness of maintaining control versus moving towards interruption of transmission and the cost-effectiveness of adding complementary interventions (such as a combined preventive chemotherapy and vector control strategy).

\section{Contextual factors that affect the cost-effectiveness of NTD programmes}

Current cost-effectiveness estimates generally represent the overall mean cost-effectiveness of a NTD preventive chemotherapy programme, or its cost-effectiveness in one specific setting. Further investigation is needed of the 
contextual factors that affect cost-effectiveness estimates and their potential variation across different settings.

A key contextual factor is the delivery cost of preventive chemotherapy. There is a need for further cost data from a wider range of settings and programmatic contexts. ${ }^{46}$ These delivery costs may be influenced by the stability and accessibility of the area (such as access to forest settings) and the costs associated with expanding treatment programmes to target harder-to-reach areas/ groups may have diseconomies of scale. ${ }^{47}$ Due to this, the cost per treatment of NTD control programmes will likely increase as end goals are approached. ${ }^{47}$

The epidemiological setting, such as the level of transmission (baseline prevalence of infection), endemic NTD species, age profile of infected individuals and historic coverage, can notably influence the cost-effectiveness of different preventive chemotherapy strategies. For example, the benefits of moving from school-based to community-wide treatment for schistosomiasis and STH depends on the burden of infection in adults. ${ }^{21} 234097$ The impact of the epidemiological setting on the generalisability of studies needs further investigation, particularly when considering a change in strategy. If such variation in epidemiological settings is not properly accounted for there is a danger that studies will be overgeneralised leading to inappropriate policy decisions.

\section{CONCLUSION}

Many studies have found preventive chemotherapy to be a cost-effective strategy for controlling several NTDs. The cost per DALY averted estimates relating to communitywide preventive chemotherapy for lymphatic filariasis and onchocerciasis were particularly favourable when other public health interventions. The estimates for schoolbased preventive chemotherapy for schistosomiasis and STH were also generally favourable but more variable. There were no estimates of cost per DALY averted relating to community-wide mass antibiotic treatment for trachoma. It is important to acknowledge that the DALYs averted metric may not be capturing the broader socioeconomic benefits for controlling these diseases.

Overall, these findings support the need for continuing NTD control and elimination efforts, providing important implications for advocacy groups, potential funders and decision-makers in endemic countries to justify the increased domestic healthcare spending needed for NTD programmes. These findings and the need for further work are increasingly important in light of the current coronavirus 2019 (COVID-19) pandemic, as there is a risk that there will be even more limited resources and financing to resume public health programmes in the coming years. ${ }^{98} 99$

Although these results are promising, it does not mean that preventive chemotherapy is a cost-effective intervention in every setting where these infections are endemic. Hence, WHO recommendations on use of different strategies depending on the endemicity of these diseases (including, at times a minimum infection prevalence threshold for mass treatment) is underlined. Accordingly, there is no one-size-fits-all approach regarding the best preventive chemotherapy strategy for controlling NTDs as this will depend on the local setting: which NTDs are endemic, at what levels of transmission, and whether the goal is controlling morbidity or interruption of transmission. Further work including cost-effectiveness analyses is needed to inform preventive chemotherapy programmes and the economics of elimination programmes.

\section{Author affiliations}

${ }^{1}$ MRC Centre for Global Infectious Disease Analysis, School of Public Health, Imperial College London, London, UK

${ }^{2}$ Oxford University Clinical Research Unit, Wellcome Africa Asia Programme, Ho Chi Minh City, Vietnam

${ }^{3}$ Centre for Tropical Medicine and Global Health, Nuffield Department of Medicine, University of Oxford, Oxford, UK

${ }^{4}$ Department of Public Health, Erasmus MC, University Medical Center Rotterdam, Rotterdam, The Netherlands

${ }^{5}$ Department of Control of Neglected Tropical Diseases, World Health Organization, Geneva, Switzerland

${ }^{6}$ Department of Tropical Disease Biology, Liverpool School of Tropical Medicine, Liverpool, UK

${ }^{7}$ Big Data Institute, Li Ka Shing Centre for Health Information and Discovery, University of Oxford, Oxford, UK

Twitter Hugo C Turner @hugocturner and Jaspreet Toor @jaspreet_toor9

Contributors HCT and JT conceived the manuscript. HCT conducted the literature searches and wrote the original draft. WAS, AWS, JDK, AM, DHM and JT contributed to the writing, reviewing and editing of the draft. All authors read and approved the final draft.

Funding HCT was supported by the Wellcome Trust core grant (106680/Z/14/Z). HCT and JT acknowledge funding from the MRC Centre for Global Infectious Disease Analysis (reference MR/R015600/1), jointly funded by the UK Medical Research Council (MRC) and the UK Foreign, Commonwealth \& Development Office (FCDO), under the MRC/FCDO Concordat agreement and is also part of the EDCTP2 programme supported by the European Union. JT and WAS gratefully acknowledge funding of the NTD Modelling Consortium by the Bill \& Melinda Gates Foundation [OPP1184344].

Competing interests DHM is a Sightsavers Consultant.

Patient consent for publication Not required.

Provenance and peer review Not commissioned; externally peer reviewed.

Data availability statement All data relevant to the study are included in the article.

Open access This is an open access article distributed under the terms of the Creative Commons Attribution IGO License (CC BY 3.0 IGO), which permits use, distribution, and reproduction in any medium, provided the original work is properly cited. In any reproduction of this article there should not be any suggestion that WHO or this article endorse any specific organization or products. The use of the WHO logo is not permitted. This notice should be preserved along with the article's original URL.

Disclaimer: The author is a staff member of the World Health Organization. The author alone is responsible for the views expressed in this publication and they do not necessarily represent the views, decisions or policies of the World Health Organization.

\section{REFERENCES}

1 World Health Organization. Neglected tropical diseases. Available: http://www.who.int/neglected_diseases/diseases/en/

2 Gabrielli A-F, Montresor A, Chitsulo L, et al. Preventive chemotherapy in human helminthiasis: theoretical and operational aspects. Trans R Soc Trop Med Hyg 2011;105:683-93.

3 World Health Organization. Preventive chemotherapy in human helminthiasis: coordinated use of anthelminthic drugs in control 
interventions: a manual for health professionals and programme managers Geneva: who, 2006. Available: https://www.who.int/ neglected_diseases/resources/9241547103/en/

4 Waters HR, Rehwinkel JA, Burnham G. Economic evaluation of Mectizan distribution. Tropical Medicine and International Health 2004;9:A16-25.

5 African Programme for Onchocerciasis Control. Revitalising health care delivery in sub-Saharan Africa. The potential of communitydirected interventions to strengthen health system. Available: http:// www.afro.who.int/sites/default/files/2017-06/EN_HealthCare07_7 3_08.pdf

6 WHO TDR. Community Directed Treatment with Ivermectin: Report of a multi-country study, 1996[(TDR/AFT/RP/96.1)]. Available from. Available: https://www.who.int/tdr/publications/tdr-researchpublications/ivermectin-cd/en/

7 Hotez PJ, Bundy DAP, Beegle K, et al. Helminth Infections: Soiltransmitted Helminth Infections and Schistosomiasis. In: Jamison DT, Breman JG, Measham AR, eds. Disease control priorities in developing countries (second edition. New York: Oxford University Press, 2006.

8 World Health Organization. Prevention and control of schistosomiasis and soil-transmitted helminthiasis 2002 [2003/02/21:[i-vi, 1-57, back cover]. Available: https://www.who.int/ intestinal_worms/resources/who_trs_912/en/912

9 Solomon AW, Akudibillah J, Abugri P, et al. Pilot study of the use of community volunteers to distribute azithromycin for trachoma control in Ghana. Bull World Health Organ 2001;79:8-14.

10 World Health Organization. Contribution of pharmaceutical companies to the control of neglected tropical diseases. Available: http://www.who.int/neglected diseases/pharma contribution/en/

11 World Health Organization. Ending the neglect to attain the sustainable development goals: a road map for neglected tropical diseases 2021-2030, 2020. Available: https://apps.who.int/iris/ handle/10665/338565

12 World Health Organization. Update on the global status of implementation of preventive chemotherapy (PC), 2020. Available: https://www.who.int/neglected_diseases/preventive_ chemotherapy/PC_Update.pdf

13 World Health Organization. Working to overcome the global impact of neglected tropical diseases: first who report on neglected tropical diseases, 2010. Available: https://www.who.int/neglected_ diseases/resources/9789241564090/en/

14 de Vlas SJ, Stolk WA, le Rutte EA, et al. Concerted efforts to control or eliminate neglected tropical diseases: how much health will be gained? PLoS Negl Trop Dis 2016;10:e0004386.

15 Fitzpatrick C, Nwankwo U, Lenk E, et al. An Investment Case for Ending Neglected Tropical Diseases. In: Holmes KK, Bertozzi S, Bloom BR, eds. Major infectious diseases. Washington (DC): The International Bank for Reconstruction and Development / The World Bank, 2017.

16 Redekop WK, Lenk EJ, Luyendijk M, et al. The socioeconomic benefit to individuals of achieving the 2020 targets for five preventive chemotherapy neglected tropical diseases. PLoS Negl Trop Dis 2017;11:e0005289-e89.

17 Chami GF, Bundy DAP. More medicines alone cannot ensure the treatment of neglected tropical diseases. Lancet Infect Dis 2019;19:e330-6.

18 Malecela MN. Reflections on the decade of the neglected tropical diseases. Int Health 2019;11:338-40.

19 Engels D, Zhou X-N. Neglected tropical diseases: an effective global response to local poverty-related disease priorities. Infect Dis Poverty 2020:9:10.

20 Gedge LM, Bettis AA, Bradley MH, et al. Economic evaluations of lymphatic filariasis interventions: a systematic review and research needs. Parasit Vectors 2018;11:75.

21 Turner HC, Truscott JE, Hollingsworth TD, et al. Cost and costeffectiveness of soil-transmitted helminth treatment programmes: systematic review and research needs. Parasit Vectors 2015;8:355.

22 Turner HC, Walker M, Pion SDS, et al. Economic evaluations of onchocerciasis interventions: a systematic review and research needs. Trop Med Int Health 2019;24:788-816.

23 Turner HC, French MD, Montresor A, et al. Economic evaluations of human schistosomiasis interventions: a systematic review and identification of associated research needs. Wellcome Open Res 2020;5:45.

24 Gold MR, Stevenson D, Fryback DG. Halys and QALYS and DALYS, $\mathrm{OH}$ my: similarities and differences in summary measures of population health. Annu Rev Public Health 2002;23:115-34.

25 Turner HC, Walker M, French MD, et al. Neglected tools for neglected diseases: mathematical models in economic evaluations. Trends Parasitol 2014;30:562-70.
26 Ahuja A, Baird S, Hicks JH. Economics of Mass Deworming Programs. In: Bundy DAP, Nd S, Horton S, eds. Child and adolescent health and development. 3rd edition. Washington (DC): The International Bank for Reconstruction and Development / The World Bank, 2017.

27 Hotez PJ, Alvarado M, Basáñez M-G, et al. The global burden of disease study 2010: interpretation and implications for the neglected tropical diseases. PLoS Negl Trop Dis 2014;8:e2865.

28 Salomon JA, Vos T, Hogan DR, et al. Common values in assessing health outcomes from disease and injury: disability weights measurement study for the global burden of disease study 2010 . The Lancet 2012;380:2129-43.

29 Taylor HR, Jonas JB, Keeffe J, et al. Disability weights for vision disorders in global burden of disease study. The Lancet 2013;381:23.

30 Salomon JA, Vos T, Murray CJL. Disability weights for vision disorders in Global Burden of Disease study - Authors' reply. The Lancet 2013;381:23-4.

31 Lo NC, Bogoch II, Blackburn BG, et al. Comparison of community-wide, integrated mass drug administration strategies for schistosomiasis and soil-transmitted helminthiasis: a cost-effectiveness modelling study. Lancet Glob Health 2015;3:e629-38.

32 Lo NC, Lai Y-S, Karagiannis-Voules D-A, et al. Assessment of global guidelines for preventive chemotherapy against schistosomiasis and soil-transmitted helminthiasis: a costeffectiveness modelling study. Lancet Infect Dis 2016;16:1065-75.

33 Goldberg EM, Pigott D, Shirude S, et al. Underestimation of the global burden of schistosomiasis - Authors' reply. The Lancet 2018;391:308.

34 King $\mathrm{CH}$, Galvani AP. Underestimation of the global burden of schistosomiasis. The Lancet 2018;391:307-8.

35 King CH, Dickman K, Tisch DJ. Reassessment of the cost of chronic helmintic infection: a meta-analysis of disability-related outcomes in endemic schistosomiasis. Lancet 2005;365:1561-9.

36 Montresor A, Trouleau W, Mupfasoni D, et al. Preventive chemotherapy to control soil-transmitted helminthiasis averted more than 500000 DALYs in 2015. Trans $R$ Soc Trop Med Hyg 2017; 111:457-63.

37 Taylor-Robinson DC, Maayan N, Soares-Weiser K, et al. Deworming drugs for soil-transmitted intestinal worms in children: effects on nutritional indicators, haemoglobin, and school performance. Cochrane Database Syst Rev 2015;7:Cd000371.

38 Bundy DAP, Kremer M, Bleakley H, et al. Deworming and development: asking the right questions, asking the questions right. PLoS Negl Trop Dis 2009;3:e362.

39 Owada K, Nielsen M, Lau CL, et al. Measuring the effect of SoilTransmitted helminth infections on cognitive function in children: systematic review and critical appraisal of evidence. Adv Parasitol 2017;98:1-37.

40 Turner HC, Truscott JE, Bettis AA, et al. Evaluating the variation in the projected benefit of community-wide mass treatment for schistosomiasis: implications for future economic evaluations. Parasit Vectors 2017;10:213.

41 Colebunders R, Titulaer MJ. Nodding syndrome: preventable and treatable. Sci Trans/ Med 2017;9:eaam8532.

42 Chesnais CB, Nana-Djeunga HC, Njamnshi AK, et al. The temporal relationship between onchocerciasis and epilepsy: a populationbased cohort study. Lancet Infect Dis 2018;18:1278-86.

43 Ton TGN, Mackenzie C, Molyneux DH. The burden of mental health in lymphatic filariasis. Infect Dis Poverty 2015;4:34.

44 Kuper H. Neglected tropical diseases and disability-what is the link? Trans R Soc Trop Med Hyg 2019;113:839-44.

$45 \mathrm{King} \mathrm{CH}$. Health metrics for helminth infections. Acta Trop 2015;141:150-60.

46 Fitzpatrick C, Fleming FM, Madin-Warburton M, et al. Benchmarking the cost per person of mass treatment for selected neglected tropical diseases: an approach based on literature review and meta-regression with web-based software application. PLoS Negl Trop Dis 2016;10:e0005037-e37.

47 Turner HC, Toor J, Hollingsworth TD. Economic evaluations of mass drug administration: the importance of economies of scale and scope. Clinical infectious diseases 2017.

48 Ndyomugyenyi R, Lakwo T, Habomugisha P, et al. Progress towards the elimination of onchocerciasis as a public-health problem in Uganda: opportunities, challenges and the way forward. Ann Trop Med Parasitol 2007;101:323-33.

49 Katabarwa M, Mutabazi D, Richards F. The community-directed, ivermectin-treatment programme for onchocerciasis control in Uganda--an evaluative study (1993-1997). Ann Trop Med Parasitol 1999:93:727-35. 
50 Katabarwa MN, Habomugisha P, Richards FO. Implementing community-directed treatment with ivermectin for the control of onchocerciasis in Uganda (1997-2000): an evaluation. Ann Trop Med Parasitol 2002:96:61-73.

51 Conteh L, Engels T, Molyneux DH. Socioeconomic aspects of neglected tropical diseases. The Lancet 2010;375:239-47.

52 Turner HC, Bundy DAP. Programmatic implications of the TUMIKIA trial on community-wide treatment for soil-transmitted helminths: further health economic analyses needed before a change in policy. Parasit Vectors 2020;13:102.

53 Turner HC, Toor J, Bettis AA, et al. Valuing the unpaid contribution of community health volunteers to mass drug administration programs. Clin Infect Dis 2019;68:1588-95.

54 WHO-CHOICE. Making choices in health: who guide to costeffectiveness analysis. Geneva: World Health Organization, 2003.

55 Drummond MF, Sculpher MJ, Torrance GW. Methods for the economic evaluation of health care programme. Third edition. Oxford: Oxford University Press, 2005.

56 Molyneux DH. The 'Neglected Tropical Diseases': now a brand identity; responsibilities, context and promise. Parasit Vectors 2012;5:23.

57 Turner HC, Bettis AA, Chu BK, et al. Investment success in public health: an analysis of the cost-effectiveness and cost-benefit of the global programme to eliminate lymphatic filariasis. Clin Infect Dis 2017:64:728-35.

58 Hernando Y, Colwell K, Wright BD. Doing well while fighting river blindness: the alignment of a corporate drug donation programme with responsibilities to shareholders. Trop Med Int Health 2016;21:1304-10.

59 De Neve J-W, Andriantavison RL, Croke K, et al. Health, financial, and education gains of investing in preventive chemotherapy for schistosomiasis, soil-transmitted helminthiases, and lymphatic filariasis in Madagascar: a modeling study. PLoS Negl Trop Dis 2018;12:e0007002

60 Becker-Dreps SI, Biddle AK, Pettifor A, et al. Cost-Effectiveness of adding bed net distribution for malaria prevention to antenatal services in Kinshasa, Democratic Republic of the Congo. Am J Trop Med Hyg 2009;81:496-502.

61 Wiseman V, PHILLIPS-HOWARD PA, MILLS J, Hawley WA, ter Kuile $\mathrm{FO}$, et al. The cost-effectiveness of permethrin-treated bed nets in an area of intense malaria transmission in Western Kenya. Am J Trop Med Hyg 2003;68:161-7.

62 Hanson K, Kikumbih N, Armstrong Schellenberg J, et al. CostEffectiveness of social marketing of insecticide-treated nets for malaria control in the United Republic of Tanzania. Bull World Health Organ 2003;81:269-76.

63 Horton S, Gelband H, Jamison D, et al. Ranking 93 health interventions for low- and middle-income countries by costeffectiveness. PLoS One 2017:12:e0182951.

64 Ochalek J, Lomas J, Claxton K. Cost per DALY averted thresholds for low- and middle-income countries: evidence from cross country data: University of York, centre for health economics, working paper 122, 2015. Available: https://pure.york.ac.uk/portal/ en/publications/cost-per-daly-averted-thresholds-for-low-andmiddleincome-countries(12487fa5-e63f-4ac3-9fa4-03b2795065eb). $\mathrm{html}$

65 Woods B, Revill P, Sculpher M, et al. Country-Level costeffectiveness thresholds: initial estimates and the need for further research. Value Health 2016;19:929-35.

66 Horton S. Cost-Effectiveness Analysis in Disease Control Priorities. In: Disease control priorities (third edition): volume 9, disease control priorities. Third Edition. Washington, DC: World Bank, 2017.

67 Hamory J, Miguel E, Walker M, et al. Twenty-Year economic impacts of deworming. Proc Natl Acad Sci U S A 2021;118. doi:10.1073/pnas.2023185118. [Epub ahead of print: 06 Apr 2021] https://www.nber.org/papers/w27611

68 Solomon AW, Holland MJ, Alexander NDE, et al. Mass treatment with single-dose azithromycin for trachoma. N Engl J Med 2004:351:1962-71.

69 Amza A, Kadri B, Nassirou B, et al. A cluster-randomized trial to assess the efficacy of targeting trachoma treatment to children. Clin Infect Dis 2017;64:743-50

70 Krentel A, Fischer PU, Weil GJ. A review of factors that influence individual compliance with mass drug administration for elimination of lymphatic filariasis. PLoS Negl Trop Dis 2013;7:e2447.

71 Bailey F, Mondragon-Shem K, Haines LR, et al. Cutaneous leishmaniasis and co-morbid major depressive disorder: a systematic review with burden estimates. PLoS Negl Trop Dis 2019;13:e0007092.
72 Webster JP, Molyneux DH, Hotez PJ, et al. The contribution of mass drug administration to global health: past, present and future. Phil. Trans. R. Soc. B 2014;369:20130434-34.

73 Krotneva SP, Coffeng LE, Noma M, et al. African program for onchocerciasis control 1995-2010: impact of annual ivermectin mass treatment on off-target infectious diseases. PLOS Negl Trop Dis 2015;9:e0004051.

74 Kositz C, Talina J, Diau J, et al. Incidental mosquitocidal effect of an ivermectin mass drug administration on Anopheles farauti conducted for scabies control in the Solomon Islands. Trans $R$ Soc Trop Med Hyg 2017;111:97-101.

75 Coscione S, Esau T, Kekeubata E, et al. Impact of ivermectin administered for scabies treatment on the prevalence of head lice in Atoifi, Solomon Islands. PLoS Negl Trop Dis 2018;12:e0006825.

76 Marks M, Vahi V, Sokana O, et al. Impact of community mass treatment with azithromycin for trachoma elimination on the prevalence of yaws. PLoS Negl Trop Dis 2015;9:e0003988.

77 Marks M, Bottomley C, Tome H, et al. Mass drug administration of azithromycin for trachoma reduces the prevalence of genital Chlamydia trachomatis infection in the Solomon Islands. Sex Transm Infect 2016;92:261-5.

78 Porco TC, Gebre T, Ayele B, et al. Effect of mass distribution of azithromycin for trachoma control on overall mortality in Ethiopian children. JAMA 2009;302:962-8.

79 Keenan JD, Bailey RL, West SK, et al. Azithromycin to reduce childhood mortality in sub-Saharan Africa. N Engl J Med Overseas Ed 2018;378:1583-92.

80 Romani L, Marks M, Sokana O, et al. Feasibility and safety of mass drug coadministration with azithromycin and ivermectin for the control of neglected tropical diseases: a single-arm intervention trial. Lancet Glob Health 2018;6:e1132-8.

81 Marks M, Gwyn S, Toloka H, et al. Impact of Community Treatment With Ivermectin for the Control of Scabies on the Prevalence of Antibodies to Strongyloides stercoralis in Children. Clin Infect Dis 2020;71:3226-8.

82 Marks M, Toloka H, Baker $\mathrm{C}$, et al. Randomized trial of community treatment with azithromycin and ivermectin mass drug administration for control of scabies and impetigo. Clin Infect Dis 2019:68:927-33.

83 Romani L, Marks M, Sokana O, et al. Efficacy of mass drug administration with ivermectin for control of scabies and impetigo, with coadministration of azithromycin: a single-arm community intervention trial. Lancet Infect Dis 2019;19:510-8.

84 Slater HC, Foy BD, Kobylinski K, et al. Ivermectin as a novel complementary malaria control tool to reduce incidence and prevalence: a modelling study. Lancet Infect Dis 2020;20:498-508.

85 Keating J, Yukich JO, Mollenkopf S, et al. Lymphatic filariasis and onchocerciasis prevention, treatment, and control costs across diverse settings: a systematic review. Acta Trop 2014;135:86-95.

86 Brady MA, Hooper PJ, Ottesen EA. Projected benefits from integrating NTD programs in sub-Saharan Africa. Trends Parasitol 2006;22:285-91.

87 Bangert M, Bancalari P, Mupfasoni D, et al. Provision of deworming intervention to pregnant women by antenatal services in countries endemic for soil-transmitted helminthiasis. PLoS Negl Trop Dis 2019;13:e0007406.

88 Boselli G, Yajima A, Aratchige PE, et al. Integration of deworming into an existing immunisation and vitamin $A$ supplementation campaign is a highly effective approach to maximise health benefits with minimal cost in Lao PDR. Int Health 2011;3:240-5.

89 Shuford KV, Turner HC, Anderson RM. Compliance with anthelmintic treatment in the neglected tropical diseases contro programmes: a systematic review. Parasit Vectors 2016;9:29.

90 Gardon J, Gardon-Wendel N, Demanga-Ngangue N, et al. Serious reactions after mass treatment of onchocerciasis with ivermectin in an area endemic for Loa loa infection. The Lancet 1997;350:18-22.

91 Boussinesq M. Loiasis. Ann Trop Med Parasitol 2006;100:715-31.

92 The Mectizan $₫$ Expert Committee and The Technical Consultative Committee. Recommendations for the treatment of onchocerciasis with Mectizan $\otimes$ in areas co-endemic for onchocerciasis and loiasis, 2004. Available: https://www.who.int/apoc/publications/ englishmectccloarecs-june04.pdf

93 Lenk EJ, Moungui HC, Boussinesq M, et al. A Test-and-Not-Treat strategy for onchocerciasis elimination in Loa loa-coendemic areas: cost analysis of a pilot in the Soa health district, Cameroon. Clin Infect Dis 2020;70:1628-35.

94 World Health Organization. Guideline: alternative mass drug administration regimens to eliminate lymphatic filariasis Geneva: World Health organization, 2017. Available: https://apps.who.int/ iris/handle/10665/259381 
95 Molyneux DH, Nantulya VM. Linking disease control programmes in rural Africa: a pro-poor strategy to reach Abuja targets and millennium development goals. BMJ 2004;328:1129-32.

96 Bockarie MJ, Pedersen EM, White GB, et al. Role of vector control in the global program to eliminate lymphatic filariasis. Annu Rev Entomol 2009;54:469-87.

97 Toor J, Rollinson D, Turner HC, et al. Achieving elimination as a public health problem for Schistosoma mansoni and $\mathrm{S}$. haematobium: when is community-wide treatment required? $\mathrm{J}$ Infect Dis 2020;221:S525-30.

98 Molyneux DH, Aboe A, Isiyaku S, et al. COVID-19 and neglected tropical diseases in Africa: impacts, interactions, consequences. Int Health 2020;12:367-72.

99 Toor J, Adams ER, Aliee M, et al. Predicted impact of COVID-19 on neglected tropical disease programs and the opportunity for innovation. Clin Infect Dis 2021;72:1463-6.

100 World Health Organization. Accelerating work to overcome the global impact of NTDs: 2011-2020 progress dashboard. Available: https://www.who.int/teams/control-of-neglected-tropical-diseases/ progress-dashboard-2011-2020

101 World Health Organization. PCT databank. Available: https://www. who.int/neglected_diseases/preventive_chemotherapy/ff/en/

102 Remme JHF, Feenstra P, Lever PR, et al. Tropical diseases targeted for elimination: chagas disease, lymphatic dilariasis, onchocerciasis, and leprosy. In: Jamison DT, Breman JG, Measham AR, eds. Disease control priorities in developing countries (second edition. New York: Oxford University Press, 2006: 433-49.

103 Coffeng LE, Stolk WA, Zouré HGM, et al. African programme for onchocerciasis control 1995-2015: model-estimated health impact and cost. PLoS Negl Trop Dis 2013;7:e2032.

104 Turner HC, Walker M, Churcher TS, et al. Reaching the London Declaration on neglected tropical diseases goals for onchocerciasis: an economic evaluation of increasing the frequency of ivermectin treatment in Africa. Clin Infect Dis 2014;59:923-32.

105 GiveWell. Errors in DCP2 cost-effectiveness estimate for deworming. Available: http://blog.givewell.org/2011/09/29/errorsin-dcp2-cost-effectiveness-estimate-for-deworming/

106 GiveWell. Cost-Effectiveness in \$/DALY for Deworming Interventions. Available: https://www.givewell.org/international/ technical/programs/deworming/cost-effectiveness

107 Chan M.S. The global burden of intestinal nematode infections fifty years on. Parasitology Today 1997;13:438-43.

108 Miguel E, Kremer M. Worms: identifying impacts on education and health in the presence of treatment externalities. Econometrica 2004;72:159-217.
109 Warren KS, Bundy DAP, Anderson RM, et al. Helminth infections. in: disease control priorities in developing countries. Oxford: Oxford University Press 1993:131-60.

110 Turner HC, Lauer JA, Tran BX, et al. Adjusting for inflation and currency changes within health economic studies. Value in Health 2019;22:1026-32.

111 Evans JR, Solomon AW, Kumar R, et al. Antibiotics for trachoma. Cochrane Database Syst Rev 2019;354:Cd001860.

112 Evans TG, Ranson MK, Kyaw TA, et al. Cost effectiveness and cost utility of preventing trachomatous visual impairment: lessons from 30 years of trachoma control in Burma. Br J Ophthalmol 1996;80:880-9.

113 Baltussen RMPM, Sylla M, Frick KD, et al. Cost-Effectiveness of trachoma control in seven world regions. Ophthalmic Epidemiol 2005;12:91-101.

114 Baltussen R, Smith A. Cost effectiveness of strategies to combat vision and hearing loss in sub-Saharan Africa and South East Asia: mathematical modelling study. BMJ 2012;344:e615-e15.

115 Burton MJ, Mabey DCW. The global burden of trachoma: a review. PLoS Negl Trop Dis 2009;3:e460-e60.

116 Solomon AW, Mabey DCW, Gilbert C, et al. Don't let misinformation derail the trachoma elimination programme. BMJ 2012;344:e2579. author reply e88.

117 Newall AT, Jit M, Hutubessy R. Are current cost-effectiveness thresholds for low- and middle-income countries useful? examples from the world of vaccines. Pharmacoeconomics 2014;32:525-31.

118 Marseille E, Larson B, Kazi DS, et al. Thresholds for the costeffectiveness of interventions: alternative approaches. Bull World Health Organ 2015;93:118-24.

119 Leech AA, Kim DD, Cohen JT, et al. Use and misuse of costeffectiveness analysis thresholds in low- and middle-income countries: trends in Cost-per-DALY studies. Value Health 2018;21:759-61.

120 WHO Commission on Macroeconomics Health, World Health Organization. Macroeconomics and health: investing in health for economic development : executive summary / report of the Commission on Macroeconomics and Health. Geneva: World Health Organization, 2001

121 World Bank. GDP per capita (current US\$) - Low income. Available: https://data.worldbank.org/indicator/NY.GDP.PCAP.CD?locations= XM

122 Shillcutt SD, Walker DG, Goodman CA, et al. Cost effectiveness in low- and middle-income countries: a review of the debates surrounding decision rules. Pharmacoeconomics 2009;27:903-17. 